\title{
EDUCAÇÃO TRANSFORMADORA EM ESPAÇOS NÃO FORMAISS: TRILHA SENSORIAL E AMBIENŢAL COMO ESTRATÉGIA DE RE-SENSIBILIZAÇÃO PARA IDOSOS
}

\section{TRANSFORMING EDUCATION IN NON-FORMAL SPACES: SENSORY AND ENVIRONMENTAL TRACK AS A RE- SENSITIZATION STRATEGY FOR ELDERLY}

\author{
Nain Nogára* \\ Aléxia Santos Amaral** \\ Ariadne de Freitas Leonardi*** \\ Débora Carla de Oliveira Freitas ${ }^{* * * *}$ \\ Gabriela Barros Silva**** \\ Giane Arruda Vargas Castanho****** \\ Lara de Oliveira Mineiro******* \\ Magliane Maciel Cardoso* \\ Márcia Prado Amaral Rosa ${ }^{* * * * * * * * *}$ \\ Maria de Fatima Ribeiro Chicatte Lima \\ Mariana Lucas de Oliveira ${ }^{* * * * * * * * * * *}$ \\ Morgana Lazzaretti \\ Ramiro da Silva Almeida \\ Rayana Piovesan* \\ Ricardo de Mello da Silva \\ Sabrina Antunes Ferreira* \\ Vanessa Mattana Nascimento dos Santos \\ Andréa Inês Goldschmidt
}

\section{RESUMO:}

$\mathrm{O}$ artigo tem como objetivo relatar a experiência vivenciada pelos alunos do curso de Ciências Biológicas da Universidade Federal de Santa Maria, durante a realizacão do projeto extensionista "Educacão transformadora em espaços não formais: trilha sensorial e ambiental como estratégia de resensibilização para idosos", realizado na Instituição Lar dos Idosos São Vicente de Paulo, durante o Estágio Curricular das Ciências Biológicas em Espaços Educativos, no primeiro semestre de 2018. O projeto trabalhou com os idosos o sistema sensorial através do tato, visão, audição e olfativo, de forma dinâmica e preocupada em restabelecer o lado individual do idoso de forma a trabalhar a percepcão e a memória, além da motivação pelos elementos ambientais. Após a aplicação do projeto, foram realizadas entrevistas que revelaram que a experiência foi significativa para os participantes, atendendo aos objetivos, alem de proporcionar aos acadêmicos novos olhares sobre o ensino-aprendizagem em espaços educativos não formais.

Palavras-chave: Espaços não formais; Estágio Curricular; Sistema Sensorial.

\section{ABSTRACT:}

This article aims to report the experience of Biological Sciences students of the University Federal de Santa Maria during the extension project "Transforming education in non - formal spaces: sensorial and environmental track as a strategy for resensitization of the elderly", held at the Institution Home of the Elderly São Vicente de Paulo, during the Curricular Internship of the Biological Sciences in Educational Spaces, in the first half of 2018. The project worked on the elderly's sensory system through touch, vision, hearing and smell, in a dynamic way and concerned to restore the elderly's individuality in order to work their perception and memory, and motivate them through environmental elements. After the implementation of the project, the interviews carried out revealed that the experience was significant among the elderly, achieving the objectives, as well as providing the students with new insights about teaching and learning in non-formal educational settings.

Keywords: Non-formal Spaces; Curricular Internship; Sensory System.

* Aluna de Graduação da Universidade Federal de Santa Maria (UFSM), Palmeira das Missões - RS, Brasil. E- mail:

nainnogara@hotmail.com

** Aluna de Graduação da Universidade Federal de Santa Maria (UFSM), Palmeira das Missões - RS, Brasil. E-mail:

alexiaamaral79@hotmail.com

* Aluna de Graduação da Universidade Federal de Santa Maria (UFSM), Palmeira das Missões - RS, Brasil. E-mail

ariadneleonardi@hotmail.com

Aluna de Graduação da Universidade Federal de Santa Maria (UFSM), Palmeira das Missões - RS, Brasil. E-mail: debora08freitas@gmail.com

* Aluna de Graduação da Universidade Federal de Santa Maria (UFSM), Palmeira das Missões - RS, Brasil. E-mail: gabriela3303@hotmail.com

Aluna de Graduação da Universidade Federal de Santa Maria (UFSM), Palmeira das Missões - RS, Brasil. E-mail: gianearrudavargas@hotmail.com

Aluna de Graduação da Universidade Federal de Santa Maria (UFSM), Palmeira das Missões - RS, Brasil. E-mail: laramineiro@hotmail.com

Aluna de Graduação da Universidade Federal de Santa Maria (UFSM), Palmeira das Missões - RS, Brasil. E-mail: maglianemacielcardoso@gmail.com

Aluna de Graduacão da Universidade Federal de Santa Maria (UFSM), Palmeira das Missões - RS, Brasil. E-mail: marciapradorosa@gmail.com

Licenciada em Ciências Biológicas. Universidade Federal de Santa Maria (UFSM), Palmeira das Missões - RS, Brasil. E-mail: mchicatte1995@gmail.com

Aluna de Graduação da Universidade Federal de Santa Maria (UFSM), Palmeira das Missões - RS, Brasil. E-mail: marianalucaszoot@gmail.com Aluna de Graduação da Universidade Federal de Santa Maria (UFSM), Palmeira das Missões - RS, Brasil. E-mail: morgana26lipe29@gmail.com Aluno de Graduação da Universidade Federal de Santa Maria (UFSM), Palmeira das Missões - RS, Brasil. E-mail: ramiroalmeida1@hotmail.com Licenciada em Ciências Biológicas. Universidade Federal de Santa Maria (UFSM), Palmeira das Missões - RS, Brasil. E-mail: raayelauterio@gmail.com Aluno de Graduação da Universidade Federal de Santa Maria (UFSM), Palmeira das Missões - RS, Brasil. E-mail: rycardo-mello@hotmail.com

Aluna de Graduação da Universidade Federal de Santa Maria (UFSM), Palmeira das Missões - RS, Brasil. Email: sabrinaantunesferreira@hotmail.com

Aluna de Graduação da Universidade Federal de Santa Maria (UFSM), Palmeira das Missões - RS, Brasil. Pr.com Professora da Unia (UFSM), Palmeira das Missões - RS, Brasil. E-mail: 


\section{Introdução}

$\mathrm{O}$ artigo apresenta uma pesquisa referencial e se estabelece como um relato de experiências em um projeto desenvolvido no Estágio Curricular Supervisionado das Ciências Biológicas em Espaços Educativos do curso de Ciências Biológicas da Universidade Federal de Santa Maria, no primeiro semestre de 2018. Este estágio tem por objetivo proporcionar experiências de ensino em espaços não vinculados à sala de aula, sendo importante essa inserção, para que os futuros professores possam compreender o processo educacional e a própria produção de conhecimento também fora do contexto escolar.

Lima e Oliveira (2013) destacam que a área de atuação dos professores ficou por muito tempo restrita aos espaços escolares; entretanto, existem inúmeros locais que podem também ser considerados como espaços de ensino. A escolha da realização das práticas pedagógicas fora do ambiente escolar se justifica quando se pensa na imersão em outras realidades e se desenvolve empatia por todas as situações que se vivencia. As autoras ainda afirmam que as vivências e experiências em espaços não escolares são importantes para o desenvolvimento de saberes docentes, essenciais para o exercício profissional de futuros professores de Ciências e Biologia.

Jacobucci (2008, p. 57) classifica que "os espaços formais de Educação se referem às Instituições Educacionais, enquanto que os espaços não formais se relacionam com Instituições cuja função básica não é a Educação formal e com lugares não institucionalizados".

A disciplina envolveu a participação de 17 licenciandos e, a partir das discussões realizadas, optou-se em desenvolver o estágio por meio de um projeto de extensão, na Associação São Vicente de Paulo, particular, localizada na cidade de Palmeira das Missões, RS. A instituição apresenta moradores e internos que contribuem financeiramente de forma diferenciada, podendo ser particular (aposentadoria) ou contrapartida dos municípios conveniados. O lar abriga atualmente 58 idosos moradores e internos, separados em 30 mulheres e 28 homens. No total, a casa conta com um quadro de 20 funcionários, entre médico, enfermeira, técnicos de enfermagem, nutricionista $\mathrm{e}$ auxiliares de serviços gerais. Além disso, o Lar dos Idosos apresenta uma boa organização física, contando com refeitório, cozinha, sala de descanso, capela, quartos e área verde.

De acordo com o Art. 1 do Estatuto do Idoso, são consideradas idosas as pessoas com idade igual ou superior a 60 anos, devendo-lhes ser assegurados os direitos previstos em lei. $\mathrm{O}$ estatuto ainda aponta:

Art. 37. $\mathrm{O}$ idoso tem direito à moradia digna, no seio da família natural ou substituta, ou desacompanhado de seus familiares, quando assim o desejar, ou, ainda, em instituição pública ou privada.

§ 3o As instituições que abrigarem idosos são obrigadas a manter padrões de habitação compatíveis com as necessidades deles, bem como provê-los com alimentação regular e higiene indispensáveis às normas sanitárias e com estas condizentes, sob as penas da lei. (BRASIL, 2003, p.24).

Realizaram-se inicialmente 12 horas em visitas ao local para se observar o seu funcionamento e sua rotina, quando foram realizadas conversas com os moradores e internos, com o intuito de conhecê-los, identificar seus gostos, a rotina, as necessidades, e refletir para as possibilidades da elaboração do projeto. Durante as visitas, pode-se perceber a carência de atenção e carinho familiar; a falta de percepção do tempo e lembranças por alguns idosos; a dificuldade na motricidade e comunicação de alguns; a felicidade em receber visitas; e, a satisfação em compartilhar histórias reais ou imaginárias. A partir destas constatações, optou-se por elaborar e desenvolver um projeto extensionista sobre o uso dos sentidos e oportunizar aos moradores experiências e percepções do mundo, respeitando as individualidades relacionadas às diferentes personalidades, à idade, às vivências, às dificuldades de motricidade e necessidades especiais, dentre outras.

Assim, foram elaboradas e desenvolvidas oficinas sensoriais e ambientais, além de uma trilha para uso dos sentidos, tato, olfato e audição, justamente por constituir uma atividade na qual os participantes exploram o ambiente escolhido, para além da visão. A proposta buscou aproximar os idosos do contato também com a natureza, além de estimular e despertar, por meio da experiência adquirida, a sensibilidade, a perspectiva, a curiosidade, a compreensão e o envolvimento com as questões corporais. Ainda, oportunizar aos acadêmicos participantes experiências relacionadas ao ensino em espaços não formais e reflexões sobre estes espaços educativos.

$\mathrm{O}$ artigo tem como objetivo relatar a experiência vivenciada pelos licenciandos, durante a realização do projeto "Educação transformadora em espaços não formais: trilha sensorial e ambiental como estratégia de re-sensibilização para idosos", realizado na Instituição Lar dos Idosos São Vicente de Paulo, de acordo com as normas técnicas estabelecidas pela Lei de Diretrizes e Bases da Educação Nacional (BRASIL, 1996), presente na disciplina de Estágio Curricular Supervisionado das Ciências Biológicas em Espaços Educativos.

\section{Fundamentação Teórica}

O Estágio Curricular Supervisionado é de suma importância para a formação profissional das áreas da licenciatura, pois possibilita a prática relacionada à educação, integrado com a escola ou outros espaços de aprendizagem. Dentro desta disciplina, é possível aos alunos vivenciarem projetos de intervenção pedagógica. Lima (2008) discute que, nos cursos de formação, a perspectiva teórico-prática deve levar a refletir sobre o trabalho do docente, implicando na construção de conhecimentos da docência, estabelecendo um diálogo pedagógico com os alunos, com o papel social da escola, da universidade e as políticas que regem a educação.

Brandão (2013) discorre que a escola não é o único lugar onde a educação acontece e talvez nem seja o melhor. Para esse autor, o ensino escolar não é a única prática educacional e o professor não é o único praticante da educação. Pires e Queiros (2016) complementam, afirmando que pensar a essência do educar implica em observar os diversos espaços que não são escolares e que apresentam conteúdo 
educativo, como as ruas, festas, movimentos sociais, igrejas e outros; ou seja, locais que proporcionam educação ao longo de toda a vida.

Assim, o Estágio Curricular Supervisionado das Ciências Biológicas em Espaços Educativos assume relevância, tanto pelas implicações sociais e o compromisso que a Universidade assume na comunidade, quanto pela promoção da educação, propondo uma reflexão a respeito da educação a ser proporcionada em espaços não escolares, no seu sentindo mais amplo.

Ramos (2014) salienta que o indivíduo, ao longo de toda a trajetória de vida, adquire conhecimentos concebidos por suas próprias experiências, por relações sociais com outros indivíduos, no âmbito familiar e em instituições educadoras formais e não formais, sendo esta prática necessária e importante quando se pensa em um processo educacional que priorize a prática de atividades que favoreçam um desenvolvimento mais amplo do indivíduo.

Lima (2008) afirma que, ao realizar o estágio em forma de projeto de intervenção, o estagiário desenvolve um olhar sensível e interpretativo em relação à realidade, uma postura investigativa e uma visão de conhecimento do espaço. Estas ações desenvolvem a autonomia, a criatividade e a cooperação, formando uma comunidade em formação.

Neste contexto, projetos com idosos promovem um aprendizado tanto pessoal como profissional para os participantes, pois existe uma troca de vivência e experiência, tornando-as únicas. Além disso, ouvir as histórias de vida contadas pelos idosos faz refletir sobre a importância da afetividade, bem como a importância de estimulá-los à socialização e integração.

Segundo Mendes et al. (2005) e Neri (2008), envelhecer é um processo natural que caracteriza uma etapa da vida do homem e dá-se por mudanças físicas, psicológicas e sociais, bem como biológicas, que acometem de forma particular cada indivíduo com sobrevida prolongada e o envelhecimento pode ser compreendido como o processo de mudanças universais regulada pela genética de cada indivíduo.

Apesar de nem sempre desejada, a institucionalização em lar é um acontecimento com alguma frequência para os mais velhos. Born e Boechat (2002) afirmam que os fatores que levam à institucionalização de idosos no Brasil são: os múltiplos problemas médicos, a imobilidade, morar sozinho, viuvez, ser solteiro, não possuir fillhos, a demência, a pobreza e o isolamento social.

As instituições que abrigarem idosos são obrigadas a manter padrões de habitação compatíveis com as suas necessidades, bem como provê-los com alimentação regular e higiene indispensáveis às normas sanitárias e com estas condizentes, sob as penas da lei (BRASIL, 2003).

Desenvolver atividades educativas nestes locais consiste em conhecer mais profundamente estes ambientes, pois é preciso avaliar que atividades são adequadas ou não. Gonçalves et al. (2010) afirmam que o acompanhamento/observação do cotidiano dos idosos é fundamental para selecionar intervenções adequadas, aplicadas tanto individualmente quanto em grupo, com o intuito de melhorar a capacidade funcional principalmente no desempenho das atividades da vida diária.

Lorda (2001, s.p.) sinaliza que "para alcançar uma velhice saudável, deve ser mantida uma participação ativa em ações sociais e comunitárias". Assim, com projetos que desenvolvam atividades recreativas nos abrigos, os idosos sentem-se estimulados a viver em comunidade, podendo, por meio dessas atividades, encontrar novos significados para suas perspectivas.

Pensando na vivência oferecida pelo período inicial de observação no estágio, a proposta educativa consistiu em elaborar oficinas sensoriais e uma trilha dos sentidos, para a participação e estimulação sensorial dos idosos. Entende-se que a percepção do ambiente, as imagens, seus significados, as impressões absorvidas e os laços afetivos são únicos em cada ser humano e esta percepção individual ocorre por meio dos órgãos dos sentidos associados às atividades cerebrais. As diferentes percepções do mundo estão relacionadas às distintas personalidades, à idade, às experiências, aos aspectos socioambientais, à educação e à herança biológica.

Kammer, Dierings e Pfluck (2013) afirmam que a trilha sensitiva busca estimular também os outros sentidos, que muitas vezes parecem estar atrofiados, bem como mostrar as dificuldades que pessoas portadoras de necessidades especiais.

\begin{abstract}
A interação com o mundo e o conhecimento deste ocorre através da união e do estímulo a esses sentidos que facilitam o aprendizado e a percepção da pessoa, pois o cérebro humano é o responsável por receber e interpretar as sensações captadas pelos órgãos, transformando-as em informações que são essenciais para o corpo (GOLDSCHMIDT et al., 2008, s.p.).
\end{abstract}

Trabalhos sensoriais propõem-se a mostrar mais do que os olhos estão acostumados a ver. É o reconhecer a natureza de outra maneira, por meio da textura das folhas, e outros elementos da natureza, do aroma das flores ou o som dos pássaros e vento.

\section{Procedimentos Metodológicos}

A partir de encontros dos acadêmicos e sob orientação da professora em sala de aula, foi elaborado um projeto extensionista para ser desenvolvido no Lar dos Idosos, sobre o uso dos sentidos como estratégia de re-sensibilização para idosos. Discussões sobre o tema e como seriam realizadas as atividades sensoriais e a trilha foram se construindo a cada semana. Realizaram-se pesquisas de referenciais para a elaboração de oficinas sensoriais e trilha de interpretação da natureza.

Os acadêmicos se organizaram em grupos para montagem da trilha e das oficinas do tato, do olfato, da audição e da visão em espaços alternados no local, organizados em dia anterior à aplicação da atividade, sendo inclusive necessário levar em consideração que alguns apresentam mais dificuldades de locomoção.

Para a trilha, foi escolhido um ambiente 
fechado, uma capela de orações, de modo que os idosos não visualizassem a organização prévia. Neste espaço, foi recriado um local com elementos da natureza, como plantas, substratos, sons e aromas, a fim de que os participantes entrassem em um mundo imaginário, ao som de pássaros e água corrente, que buscasse estimular o sistema auditivo e proporcionar sensações agradáveis, valorizando todos os sentidos.

Foram utilizados sons da natureza, queima de incenso, névoa de água que era aspergida sobre os participantes com o auxílio de um borrifador. No chão estavam dispostos, areia, pedras, folhas e galhos secos, bambus e plástico bolha, intercalando com material sensorial para o tato, dispostos em recipientes e bandejas com materiais diversos (algodão, pinha, esponja vegetal, briófitas, bolinha expansiva de gel, casca de árvore, areia, plástico bolha, bolitas, plantas suculentas, sementes e animais taxidermizados). Ao término da trilha, os idosos foram conduzidos até um espelho ornamentado com folhas, bambus e flores, onde ainda com os olhos vendados, foi enfatizado que, ao retirarem a venda, visualizariam a imagem de algo muito especial. Desta forma, ao retirarem a venda, tinham a oportunidade de verem sua própria imagem refletida no espelho, promovendo a valorização da autoestima. Um dos alunos conversou com eles sobre a importância de cada um no mundo.

As oficinas sensoriais foram montadas nas salas de estar e refeitórios. Na oficina olfativa, foram escolhidos 10 aromas diferentes (alecrim, manjericão, cravo, canela, flor de jasmim, bergamota, café, hortelã, alho e perfume), postos em vidrinhos, de modo a serem aproximados perto das narinas dos idosos.

Utilizando-se uma caixa revestida, foi montada a oficina da visão, onde foram escolhidos objetos como uma pinha, relógio, vaso com planta, concha do mar, uma chave e um pote com erva-mate, a fim de ser trabalhada a memória dos idosos.

$\mathrm{Na}$ oficina do tato, os acadêmicos organizaram cinco caixas de madeira, fechadas, cada uma contendo um objeto, para que, através do toque, os idosos pudessem imaginar, adivinhar e descrever o que sentiam. Os objetos usados foram amoeba, esponja de aço, esponja vegetal, grãos de feijões e um animal taxidermizado.

Ainda, foi desenvolvida uma oficina de audição e recreação, na sala de convívio, contando com uma caixa de som, para serem ouvidas músicas.

Após a execução do projeto, foram realizadas duas visitas, no intuito de avaliar as atividades desenvolvidas. Foram realizadas entrevistas individuais e em grupo, gravadas nos celulares e transcritas para análise qualitativa, seguindo a metodologia de análise de conteúdo, proposta por Bardin (2011). Ainda fizeram parte da análise as anotações realizadas pelos acadêmicos em seus diários de campo. $\mathrm{Na}$ segunda visita, além destes procedimentos, foram usadas fotografias do dia para que os idosos lembrassem das atividades desenvolvidas, pois já haviam passado 11 dias da sua realização.

\section{Resultados e Discussões}

$\mathrm{O}$ projeto, antes de ser desenvolvido, foi discutido com os responsáveis, no intuito de avaliar se a proposta era coerente ao público, sendo relatado que muitos idosos não participavam das ações pelas limitações que possuem, porém esta parecia ser uma proposta diferenciada e atrativa. De fato, os resultados obtidos com as atividades foram significativos $\mathrm{e}$ positivos, sendo discutidos a seguir.

Nas oficinas propostas, poucos idosos iam até o espaço organizado previamente, sendo necessário adaptar as oficinas, levando-as até eles. Como se tratava de um dia com temperaturas baixas, os internos ficaram em torno da lareira e também em seus quartos, e por este motivo as oficinas circularam, possibilitando a participação deles, com resultados positivos (Figura 1).

$\mathrm{Na}$ oficina do tato, os idosos curiosos aceitavam participar e respondiam alegres, descobrindo os objetos colocados nas caixas; e, quando não conseguiam identificar, retiravam-nos da caixa. $\mathrm{Na}$ oficina do olfato, os vidrinhos eram colocados perto das narinas, de modo que os idosos sentissem o aroma e relatassem os nomes que conheciam, o que lhes remetia à lembrança. Quando não lembravam o nome, eram realizadas perguntas, de modo a estimular a memória, como: "É uma planta? O (a) senhor (a) gosta desse cheiro?". Se ainda não adivinhavam o nome exato, eram feitas colocações, como, "é parecida com manjerona!", instigando-se a chegarem no nome exato do aroma.

Boscato (2015) comenta que, quando comemos alguma coisa ou quando sentimos um aroma, isso nos traz lembranças marcantes, de sabor da infância:

\begin{abstract}
Quando criança as maçãs eram mais perfumadas e hoje parece que elas quase não têm cheiro. Não posso imaginar o que teria acontecido, se meu olfato mudou ou se as maçãs já não são mais as mesmas (...) Cheiro de grãos de café moído, de bolo no forno, de terra molhada. Os aromas e sabores faziam então parte das nossas descobertas, daquele mundo desconhecido a ser explorado. Nada era impossível, tudo tinha mais frescor (BOSCATTO, 2015, p.1).
\end{abstract}

Assim, a estimulação dos sentidos e também do corpo traz benefícios aos idosos, pois além de instigar seus pensamentos, os deixa saudosos, estimulando sua memória e, ainda, curiosos, como no caso da trilha e da oficina da visão, em que só podiam usar o tato. Goldschmidt et al. (2008 p. 3) enfatizam que "o corpo como um todo é um canal de convergência sensorial. Por sabermos que o corpo também participa do aprendizado, também sente e também se recorda, precisamos reconhecê-lo, respeitá-lo e utilizá-lo mais em nossas vidas".

$\mathrm{Na}$ oficina da visão, também foram necessárias algumas adequações na aplicação da atividade. Primeiramente, ao apresentar os objetos na caixa, só era mencionado seu nome, e eles deveriam observar e, após, identificar qual objeto havia sido retirado. Verificou-se que os idosos tiveram grandes dificuldades de memorizar no momento em que o orientador retirava o objeto da caixa, sendo assim, para que houvesse maior participação, optou-se por solicitar que eles mesmos retirassem um objeto da caixa, incentivando-se a memorização.

Flório (2015, p. 1) afirma que "O processo de 
envelhecimento deixa o indivíduo mais suscetível a perdas cognitivas, que podem ser desde falta de atenção ou esquecimentos leves até perdas graves de memória, equivalentes a um dos sintomas da demência senil".

Figura 1 - Atividade realizada nas oficinas do tato, do olfato e da visão com os idosos.

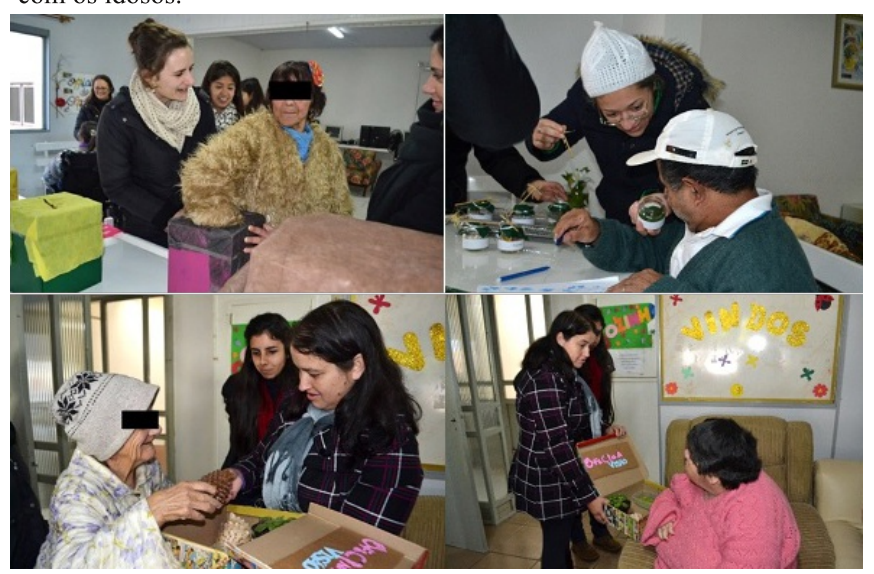

Fonte: Acervo pessoal dos autores

Durante a oficina de recreação, os idosos preferiram ficar acomodados nos sofás, ouvindo as músicas. A pouca participação provavelmente esteve associada à baixa temperatura registrada no dia, e ainda em virtude da idade avançada, ou por problemas de saúde, fadiga e sedentarismo. Silva et al. (2011) relatam que a fadiga é um sintoma presente na maior parte dos idosos, pois quando acontece o processo do envelhecimento o corpo precisa se adaptar, porém, de forma complexa, muitos fatores ajudam no aparecimento do fenômeno.

Gonçalves et al. (2010) corroboram ao afirmarem que, com o passar dos anos, ocorre um declínio na prática de exercícios físicos, o que torna o idoso dependente de outra pessoa, observando-se que em idosos moradores de asilos a situação prevalece, tornando-os institucionalizados e menos adeptos a atividades que requerem mais movimentação.

$\mathrm{Na}$ trilha, contou-se com a participação de 20 idosos, um número considerável positivo, pois a expectativa inicial era de que pelo menos 10 idosos participassem.

A trilha implicou em trazer lembranças da natureza, assim como memórias de quando mais jovens, envolvendo tanto sentidos corporais, como emocionais. Mendes et al. (2005 p. 424) afirmam que "A habilidade pessoal de se envolver, de encontrar significado para viver, provavelmente influência as transformações biológicas e de saúde que ocorrem no tempo da velhice".

No início da trilha sensorial, alguns idosos ficaram inseguros de serem vendados, outros retiravam a venda por instantes, sem comprometer o objetivo da trilha. Os moradores foram sendo guiados pelos acadêmicos (Figura 2).

Notou-se que era atrativo o momento de imaginar e perceber do que se tratava cada objeto na trilha. Na opinião de Ferreira e Barham (2011), a alegria experimentada ao participar de atividades contribui muito para a boa disposição do idoso. Estudos feitos por esses pesquisadores salientam que se ocupar de atividades prazerosas ajuda psicologicamente, o idoso consegue focar em aprendizados positivos, deixando em segundo plano qualquer dificuldade em sua vida pessoal. Kammer, Dierings e Pfluck (2013) corroboram ao afirmarem que a trilha sensitiva estimula os sentidos que muitas vezes estão atrofiados, pois, ao fazer o processo de olhos vendados, o participante pode sentir sensações que por muito tempo não sentia.

Ao final da trilha, diante do espelho, era retirada a venda e eles poderiam ver o que era mais importante naquele local. As emoções sentidas foram distintas, desde abraços calorosos, risadas, decepção ao se verem, baixa autoestima, até mesmo sensação de choro e alegria ao se sentirem valorizados pelos acadêmicos.

Ao saírem da trilha, contavam aos outros idosos, o que aumentava a curiosidade e, consequentemente, o interesse na participação.

Figura 2 - Atividade realizada nas oficinas do tato, do olfato e da visão com os idosos.

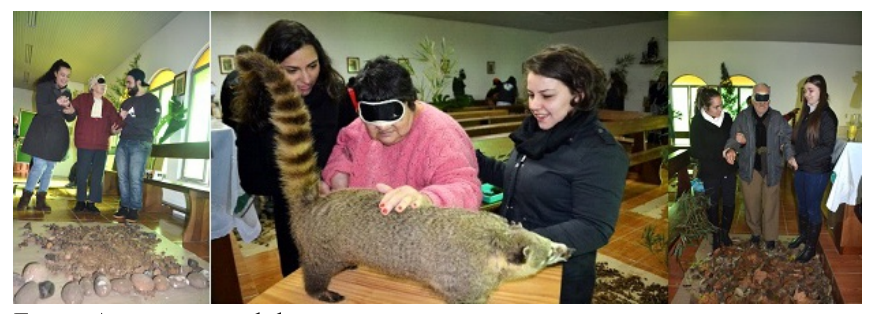

Fonte: Acervo pessoal dos autores.

As entrevistas realizadas após o desenvolvimento das atividades ocorreram em dois momentos e os resultados na primeira visita não foram muito significativos, pois nem todos lembravam. $\mathrm{Na}$ segunda visita, com o auxílio das fotos registradas, os idosos eram questionados sobre a realização do projeto. Observou-se que eles não só lembraram das atividades executadas, como também ficaram felizes ao se verem nas imagens, constatando-se, portanto, que a experiência vivenciada ainda estava na memória de alguns dos idosos.

Brady et al. (2008) relatam que relembrar coisas do passado por meio de imagens é muito mais eficaz, pois a memória visual do idoso requer menos informações, facilitando, assim, seu desempenho em resgatar lembranças. Os mesmos autores discutem que a riqueza de lembranças resgatadas mediante imagens é maior do que aquelas apenas contadas ou comentadas.

Os depoimentos dos idosos foram gravados e transcritos, sendo apresentados e discutidos a seguir, nos quais foi possível identificar cinco categorias de análise, a posteriori. São elas: (1) Lembranças associadas somente ao dia; (2) Lembranças associadas às suas histórias de vida; (3) Alegria, entusiasmo e diversão; (4) Fragilidades na memória; e, (5) Autoestima e valorização.

Transcrições e análise de conteúdo para
categorização

\section{Categoria de análise: Lembranças associadas somente ao dia}

Quando indagados pelos pesquisadores "O que você lembra daquele dia?", obtiveram-se diversas 
respostas, algumas relacionadas apenas à atividade desenvolvida. Assim, o Idoso A (2018) relatou: “...me lembro que fizeram pergunta, pediram o que que é, eu achei que era um tatu".

\section{O Idoso B (2018) relatou que:}

Eu lembro que pisei em cima de umas folhas verdes, outras folhas secas, outras não podia divulgar o que era, porque não podia enxergar né?! Aí eu pisei um barriu de pedra, como diz? Cascalho, que me falaram para andar bem devagarzinho. Pisei numa areia, aí fui indo, depois tinha um balde de flor. Depois tinha um bichinho, mas é uma raposa. (Risos).

O Idoso B ainda lembrou que tinha uma música bem baixinha ao fundo, que era muito bonita. Sobre o animal que o idoso lembrou de ter tocado, foi revelado que era um quati e não uma raposa. Quando viu a foto, o mesmo afirmou se tratar de um quati.

\section{Categoria de análise: Lembranças associadas às suas histórias de vida}

Alguns idosos associaram as atividades desenvolvidas às memórias de vida. $\mathrm{O}$ Idoso $\mathrm{C}$ relatou lembrar e reconhecer o barulho das folhas como sendo de um local que quando mais jovem passava, tratavase, segundo ele, de um caminho onde existia muitas dessas árvores. Assim, relatou "aí eu pisei naquelas folhas e descobri que eram folhas de plátano, faziam barulho de prateira! ”. (IDOSO C, 2018). Através desde depoimento, pode-se perceber que os idosos apresentam memória voltada para os fatos passados, apesar de muitas vezes terem dificuldades em lembrar acontecimentos recentes. Outro morador, o Idoso D, comentou sobre o trecho de pedras percorrido na trilha "onde morava tinha uma ponte para poder atravessar o rio". (IDOSO D, 2018), referindo-se às pedras que teve de passar. Acreditava se tratar dessa ponte.

Freitas e Costa (2011) discutem que, ao permitir o resgate de histórias do passado e a manifestação de sua opinião, os idosos sentem-se fortes psicologicamente e inseridos novamente na sociedade. Halbwachs (2004) corrobora afirmando que a lembrança é, em larga medida, uma reconstrução do passado com a ajuda de dados emprestados do presente, e que as lembranças podem ser simuladas, expandindo a própria percepção do passado.

Outro morador (Idoso E) relatou: "Do bicho, tamanduá", fazendo referência ao quati taxidermizado que foi colocado na trilha para tocarem. Porém, apesar de ser dito que se tratava de um quati, insistiu ser um tamanduá, como a narrativa transcrita mostra: "Não! É igual um quati, mas é um tamanduá'. Ao mostrar uma foto do quati para que reconhecesse, ele relatou: "Mais legal foi ver o tamanduá, igual que tinha na roça, quando ele vê a gente, fica bem de pezinho, ele se senta que nem um cachorro, e se chegar perto dele ele aperta a gente". O mesmo participante ainda relatou que, na trilha, "tinha cascas de eucalipto, cascas de taquaruçu, com capa em roda, cascas grossas de angico". Ao relatar sobre a trilha e citar as cascas de diferentes árvores, lembrou que "adorava lidar com elas no mato".

Lembrou também do dia anterior, em que os acadêmicos foram organizar o espaço para a atividade
"Era bonito, eu gostei, no dia que vieram arrumar ali eu fui lá xeretar ver o que era, eu fiquei curiosa, daí eles disseram é segredo, amanhã que a senhora vai participar" (IDOSO E, 2018).

Os depoimentos elucidam a importância da trilha percorrida para os idosos, pois, ao relatarem a experiência, recordaram-se de fatos que ocorreram em suas vidas. Goldschmidt et al. (2008 p. 4) afirmam que "O ambiente natural, assim como o ambiente construído, é percebido de acordo com os valores e as experiências individuais dos homens onde são atribuídos valores e significados em um determinado grau de importância em suas vidas".

\section{Categoria de análise: Alegria, entusiasmo e diversão}

Constatou-se que os participantes gostaram das atividades realizadas: "Bem bonito aquele dia. Coisa mais linda, estava lindo! Ensinaram nós, conversaram com nós. Nós gostamos de vocês (...)”(IDOSO F, 2018).

O Idoso B também fez menção a esta categoria de análise, em seu depoimento: "É claro que gostei! Eu gostei, muito lindo. Eles colocaram que a alegria era uma paz de quem estava caminhando ali, aí diziam para mim não deixo cair, não vai cair, eu estava segurada". (IDOSA B, 2018).

Outro se referiu à atividade como algo que alegrou muito aquele dia, como sua fala mostra: “ Alegrava, alegrava, eu adorei ver esse jardim. E fui, fui, até achei o fim que tinha um rapaz do lado, que não perguntei o nome dele afinal. Até que perguntei quem está perto de você, e é um amigo que estava perto de mim, me conduzindo" (IDOSO C, 2018).

Com os depoimentos, pode-se perceber que a atenção e o carinho com que foram tratados contribuiu de maneira significativa para o bem-estar e autoestima dos mesmos, pois demonstraram alegria e entusiasmo ao relembrarem isso. Não se pode negar o sentimento de afeto sentido pelos idosos e o quanto isto foi significativo para cada acadêmico participante. Lemos e Medeiros (2002, p.251) sinalizam que "O afeto, a ajuda mútua e a compreensão são aspectos essenciais que devem existir no relacionamento idoso/família. Assim, o convívio se torna agradável e os idosos conseguem viver de forma harmoniosa junto a seus entes queridos". Neste momento, o grupo que desenvolveu a atividade se sentiu também muito importante na vida destas pessoas, o que, de fato, é fundamental para que haja um processo de ensino e aprendizagem.

\section{Categoria de análise: Fragilidades na memória}

Ao perguntar ao Idoso $G$ se ele lembrava da atividade realizada havia alguns dias, ele respondeu que não se recordava. Mesmo ao mostrar uma foto do animal taxidermizado que foi usado na trilha, o idoso falou: "Não sei! Olha, parece um porco!". O entrevistador contou como foi feita a atividade da trilha sensitiva e mostrou várias fotos, buscando recordar a memória do entrevistado. Após algum tempo, ele exclamou: "Ah, isso eu lembro! Agora lembrei. Só me lembro que fizeram uma pergunta, pediram o que é o que, eu achei que era um tatu". Ao ser questionado se tinha gostado da atividade, o 
idoso relatou: "gostar até gosto, mas preso aqui não tem muita graça, fosse anos atrás quando eu bebia, eu bebia bastante, eu ia frouxo na trova, na cantoria, agora tô entocado aqui, não posso nem tomar uma cerveja". Ao final da entrevista, o Idoso afirmou: "fui internado por causa da bebida, e que agora não é por causa da bebida, é por causa da minha idade". (IDOSO G, 2018).

O idoso institucionalizado é geralmente uma pessoa desmotivada para a vida, sem expectativas e com esperanças de retorno ao ambiente familiar. Além disso, ele ainda se vê na condição de ter que conviver com pessoas muito diferentes, às vezes até não idosas, com doenças incapacitantes, mentais, psiquiátricas e com alcoolistas, o que torna o ambiente desconfortável. (MARIN et al., 2012, s.p.).

Os lapsos de memória foram intensos e mesmo após serem lhe mostradas as fotos, esse idoso apenas recordou de algumas situações. Isso confirma que a falta de estímulos cognitivos em idosos só agravam as falhas na memória, além de outros fatores como atenção, concentração, linguagem. Sobre isso, Carvalho (2006, p. 15) discorre que, no envelhecimento, ocorre um declínio na memória, mesmo em idosos não acometidos por patologias. Esse declínio, no envelhecimento normal, não é uniforme, ou seja, não é igual para todos os indivíduos idosos e nem para todos os subsistemas de memória.

\section{Categoria de análise: Autoestima e valorização}

Durante as entrevistas, os moradores foram questionados sobre "O que havia ao fim da trilha?". O Idoso E relatou: "Uhum, no final era aquelas folhas de taquaruçu, as capas, e o espelho depois daí, era tudo enfeitado (...) quando cheguei no espelho, já estava com as vistas abertas, daí eu disse mas e tem prêmio?" Conversou-se sobre a sua imagem ser um prêmio e o quanto é bom se achar bonito, então ele disse: "Cada dia que você vai na frente do espelho daí tu diz, hoje estou mais bonita do que ontem, rugas pra minha idade era pra estar cheia, mas não tenho nada". Comentou, ainda, que a cada dia em que se olha no espelho, pensa: "hoje estou mais bonita do que ontem! ”. (IDOSO E, 2018).

Com isso, observou-se que a parte final da trilha foi de grande importância para o mesmo, pois ao se ver no espelho, achou-se bonito, o que foi gratificante tanto para o idoso como para os entrevistadores, pois a baixa autoestima em idosos é um fator preocupante. "Muitos idosos rejeitam o próprio envelhecimento em virtude da imagem que fazem de si mesmos, desenvolvendo sentimento de autodesvalorização e de baixa autoestima" (CHAIM; IZZO; SERA, 2009, p. 176).

Outro relato importante foi a citação feita pelo Idoso $\mathrm{H}$, ao ser questionado se gostou ou não das atividades. Afirmou: "claro que gostamos". Ao perguntar se achou ruim fechar os olhos, respondeu: "eu gostei por que é bonito". Ainda, ao ser indagado sobre o que sentiu na atividade, disse: "passou uma coisa que há tempos não passava mais", e quando perguntado se havia gostado do que tinha visualizado no espelho ao final da trilha, respondeu: "gostei mais ou menos, porque era nós mesmos".

Percebe-se como significativa a afirmação sobre ter sentido algo que havia tempos não sentia, pois, através da imaginação, os idosos puderam sentir emoções diferentes das que estão habituados e possivelmente recordar momentos já vivenciados ao longo da sua vida.

Decker e Pereira (2009) afirmam que fazendo o resgate da identidade pessoal e da importância do idoso na sociedade, apesar de suas limitações, este irá perceber o seu valor, o que promoverá autoestima elevada e um envelhecimento de boa qualidade. Desta maneira, estimular os idosos para que direcionem suas vidas em algo que lhes dê prazer e satisfação pessoal aumenta a sua autoestima, fazendo com que se sintam valorizados (PORCIUNCULA; PORTO, 2014).

Por fim, ao entrevistar a responsável pelo lar, obteve-se o relato:

\begin{abstract}
Ao receber o projeto em mãos digo com toda a propriedade que foi muito emocionante, e ao ler o tema tive a certeza que para nossos idosos iria ser muito válido, pois iria trazer lembranças, conhecimentos, auto percepção e muita emoção para eles (...) Retornei cinco dias após ter acontecido o projeto e os idosos muito empolgados vieram me contar o que tinha acontecido, falaram que eu tinha perdido a atividade. A primeira coisa que me contaram foi que fecharam os olhos deles com uma "máscara" e que depois eles tinham que passar as mãos nas coisas e adivinhar o que era. Deram muita risada em me contar, pois diz que até "bicho duro" tinha. Falaram também que pisaram em folhas e até árvore tinha (RESPONSÁVEL, 2018).
\end{abstract}

Este relato elucida o quanto o projeto foi importante. Tornou-lhes possível, mesmo que por algumas horas, modificar a rotina diária e lhes proporcionou vivenciar de forma divertida e agradável o tato, a audição, o olfato e a visão, provocando memórias importantes, alegria e autoestima.

\section{Considerações finais}

Com o desenvolvimento do projeto em espaços não formais, pode-se vivenciar que ensinar não está somente posto em sala de aula, deve-se sempre buscar, planejar e atender o sujeito educando, independentemente de seu meio social, ambiental e de saúde, servindo a experiência de estímulo para reflexões sobre os espaços educativos.

Ao avaliar os resultados, compreende-se o quanto o docente é importante como agente formador de mudanças na sociedade, à medida que há esta relação intencional também em outros espaços educativos. O educador e o educando, ao compartilharem experiências, tornam significativos os conhecimentos mútuos que são ensinados e apreendidos com a convivência.

Durante a elaboração do projeto, os acadêmicos apresentaram anseio em desenvolver as atividades com os idosos. Igualmente, no momento do diagnóstico, mostravam-se receosos nas conversas. Aos poucos, foram se adaptando às situações, estabelecendo-se assim um ambiente de descontração, o que deixou os estagiários seguros e os idosos curiosos. Isso foi muito importante, pois gerou um ambiente de envolvimento com vários aprendizados, tanto pessoal como profissional para os acadêmicos, pois promoveu uma grande troca de vivência, tornando-a uma experiência educativa mais humanizada e única. 


\section{Referências}

BARDIN, L. Análise de conteúdo. São Paulo: Edições 70, 2011.

BOSCATTO, E. O tempo e nossa memória sensorial. Blog Obvious. Revista digital: Por trás do espelho, 2015.

Disponível em:

http://lounge.obviousmag.org/por tras do espelho/2012/07/ o-tempo-e-nossa-memoria-sensorial.html. Acesso em: 15 fev. 2018

BORN, T.; BOECHAT, N. S. A qualidade dos cuidados ao idoso institucionalizado. Tratado de geriatria e gerontologia. Rio de Janeiro: Guanabara Koogan., 2002.

BRADY, T. F. et al. Visual long-term memory has a massive storage capacity for object details. Proceedings of the National Academy of Sciences of the United States of America, v. 105, n. 48, p. 1435-1439, 2008.

BRANDÃO, Carlos Rodrigues. O que é educação? São Paulo: Brasiliense, 2013.

BRASIL. Lei n ${ }^{\circ}$ 9.394, de 20 de dezembro de 1996. Estabelece as diretrizes e bases da educação nacional. Lei de Diretrizes e Bases da Educação-LDB. Brasília, DF, 1996.

BRASIL. Lei ${ }^{\circ} .10 .741$, de $1^{\circ}$ de outubro de 2003. Dispõe sobre o Estatuto do Idoso e dá outras providências. Diário Oficial da União, 3 out. 2003.

CARVALHO, F. C. R. Treino de memória episódica com idosos normais. 2006. 88f. Dissertação (Mestrado em Gerontologia) - UNICAMP - Faculdade de Educação. São Paulo, 2006.

CHAIM, J.; IZZO, H.; SERA, C. T. N. To care in health: satisfaction with body image and self- esteem of old people. Mundo Saúde, v.33, n.2, p.175-81, 2009.

DECKER, S.; PEREIRA, E. Trabalhando a percepção do corpo e da autoestima na terceira idade: relato de experiência. Curitiba: Centro Reichiano, 2009.

FERREIRA, H. G.; BARHAM, E. J. O Envolvimento de idosos em atividades prazerosas: Revisão da Literatura sobre Instrumentos de Aferição. Revista Brasileira de Geriatria e Gerontologia, v. 14, n. 3, p. 579-590, 2011.

FLÓRIO V. Lapsos e lembranças: a memória do idoso. Revista Pré-univespe, v. 48, 01 ago. 2015.

FREITAS, S. A. de; COSTA, M. J. da. Identidade social do idoso: memória e cultura popular. Revista Conexão, Ponta Grossa, v. 7, n.2, 2011.

GOLDSCHMIDT, A.I. et al. A importância do lúdico e dos sentidos sensoriais humanos na aprendizagem do meio ambiente. In: SEMINÁRIO INTERNACIONAL DE EDUCAÇÃ̃, 13., 2008. Anais... Cachoeira do Sul, 2008.

GONÇALVES, L. et al. O idoso institucionalizado: avaliação da capacidade funcional e aptidão física. Caderno de Saúde Pública, Rio de Janeiro, v.26, n.9, p.1738-1746, set. 2010

HALBWACHS, Maurice. A memória coletiva. São Paulo: Centauro, 2004.

JACOBUCCI, D. F. C. Contribuições dos espaços nãoformais de educação para a formação da cultura científica. Revista Em Extensão, Uberlândia, v.7, n. 1, 2008.
KAMMER, A.; DIERINGS, A. I.; PFLUCK, L. D. A Trilha Sensitiva: um trabalho de campo diferenciado no ensino da geografia. In: SEMANA ACADÊMICA E EXPEDIÇÃO GEOGRÁFICA: Ensino, práticas e formação em Geografia, 13., 2013. Anais... Disponível em: http://cacphp.unioeste.br/eventos/semanageografia/anais2013/trabalh os/resumo_expandido/geografia/33.pdf. Acesso em: 15 fev. 2018.

LEMOS N.; MEDEIROS, S. L. Suporte social ao idoso dependente In: FREITAS, E.V.; PY, L.; NERI, A.L.; CANÇADO, H.A.X.; GONZONI, M.L.; ROCHA, S.M. Tratado de geriatria e gerontologia. Rio de Janeiro (RJ): Guanabara Koogan, 2002. cap.01, p.251.

LIMA, A. R. L.; OLIVEIRA, M. C. A. A importância do estágio em espaços não escolares no projeto acadêmico curricular do curso de licenciatura em Ciências Biológicas da UESC, Ilhéus-BA. Anais.... In: ENCONTRO REGIONAL SUL DE ENSINO DE BIOLOGIA (EREBIO-SUL), 6., 2013. Anais... Universidade Regional Integrada do Alto Uruguai e das Missões - Campus de Santo Ângelo (URI), 22 a 24 de maio de 2013.

LIMA, M. S. L. Reflexões sobre o estágio/prática de ensino na formação de professores. Revista Diálogo Educacional, Curitiba, v. 8, n. 23, p. 195-205, jan./abr. 2008.

LORDA, C. R.; SANCHEZ, C. D. Recreação na terceira idade. 3. ed. Rio de Janeiro: Sprint, 2001.

MARIN, M. J. S. et al. Compreendendo a história de vida de idosos institucionalizados. Revista Brasileira de Geriatria e Gerontologia, Rio de Janeiro, v.15, n.1, 2012.

MENDES, M. R. S. S. B. et al. A situação social do idoso no Brasil: uma breve consideração. Acta Paul Enferm., v.18, n.4, 2005.

NERI, A. L. Palavras chave em gerontologia. 3.ed. Campinas: Alínea, 2008.

PIRES, C. M. S.; QUEIROS, P. P. Q. O estágio em espaços não formais de ensino: outras possibilidades do educar. In: SEMINÁRIO INTERNACIONAL DE LA RED ESTRADO: MOVIMIENTOS PEDAGÓGICOS Y TRABAJO DOCENTE EN TIEMPOS DE ESTANDARIZACIÓN, 11., 2016. Anais.... México DF, 16 a 18 de novembro de 2016.

POLLAK, M. Memória e identidade social. Estudos Históricos, Rio de Janeiro. v. 5, n. 10, p. 200-212, 1992.

PORCIUNCULA, A. S. da; PORTO, I. Envelhecimento, meio ambiente e educação ambiental. Estudos Interdisciplinares do Envelhecimento, Porto Alegre, v. 19, n. 2, p. 453-470, 2014.

RAMOS, M. F. Educação não formal: Pedagogia social transformadora e motivadora. 2014. Disponível em: https://meuartigo.brasilescola.uol.com.br/pedagogia/\%20edu cacao-nao-formal.htm. Acesso em: 15 fev. 2018

SILVA, J. P. et al. Fatores clínicos, funcionais e inflamatórios associados à fadiga muscular e à fadiga auto percebida em idosas da comunidade. Revista Brasileira de Fisioterapia, v.15, n.3, p.241-248, 2011. 